\title{
Urinary Biomarkers for Neurodegenerative Diseases
}

\author{
Wongi Seol $^{1 *}$, Hyejung $\mathrm{Kim}^{1}$ and Ilhong Son ${ }^{1,2 *}$ \\ ${ }^{1}$ InAm Neuroscience Research Center, ${ }^{2}$ Department of Neurology, Sanbon Medical Center, College of Medicine, \\ Wonkwang University, Gunpo 15865, Korea
}

Global incidence of neurodegenerative diseases (NDDs) such as Alzheimer's disease (AD) and Parkinson's disease (PD) is rapidly increasing, but the diagnosis of these diseases at their early stage is challenging. Therefore, the availability of reproducible and reliable biomarkers to diagnose such diseases is more critical than ever. In addition, biomarkers could be used not only to diagnose diseases but also to monitor the development of disease therapeutics. Urine is an excellent biofluid that can be utilized as a source of biomarker to diagnose not only several renal diseases but also other diseases because of its abundance in invasive sampling. However, urine was conventionally regarded as inappropriate as a source of biomarker for neurodegenerative diseases because it is anatomically distant from the central nervous system (CNS), a major pathologic site of NDD, in comparison to other biofluids such as cerebrospinal fluid (CSF) and plasma. However, recent studies have suggested that urine could be utilized as a source of NDD biomarker if an appropriate marker is predetermined by metabolomic and proteomic approaches in urine and other samples. In this review, we summarize such studies related to NDD.

Key words: Urine, Biomarkers, Parkinson’s disease, Alzheimer’s disease

\section{INTRODUCTION}

Neurodegenerative disease (NDD) is a general term that encompasses several brain disorders categorized by the gradual deterioration of various neuronal systems and includes Alzheimer's disease (AD), Parkinson's disease (PD), Huntington's disease (HD), amyotrophic lateral sclerosis (ALS) among others. Since the most pathologic sites in NDD are in the brain, where accessibility to obtain a biopsy sample is difficult, accurate diagnosis of NDD is challenging. Therefore, it is urgent to develop reliable diagnostic biomarkers for NDD.

Biofluids such as the cerebrospinal fluid (CSF), plasma, saliva and urine are being analyzed as sources of biomarker to diagnose,

Submitted September 4, 2020, Revised October 12, 2020,

Accepted October 19, 2020

\footnotetext{
* To whom correspondence should be addressed. Ilhong Son, TEL: 82-31-390-2486, FAX: 82-31-390-2414

e-mail: sonih@wku.ac.kr

Wongi Seol, TEL: 82-31-390-2411, FAX: 82-31-390-2414

e-mail:wseolha@gmail.com
}

monitor and treat various NDDs [1-7]. Although CSF seems to be the better source to identify NDD biomarkers, it does not reflect the early aberrant physiological condition as CSF is regulated to be homeostatic. In addition, it is difficult to sample CSF for both the patient and the clinician. In contrast, urine is a biofluid that can be obtained in abundance in invasive manner. Besides, urine reflects the systemic changes which can be investigated through proteomic and metabolomic analysis. Accordingly, recent studies elucidate the potential of urine as a biomarker source for NDD [813]. One disadvantage of using urine as a biomarker source is the low concentration of bioactive material in urine. However, it can be overcome either by increasing their concentrations in urine using various methods such as microfiltration and fractionation [13] or by the isolation of urine exosomes [1].

\section{DETECTION METHODS}

A good biomarker and its assay for diagnostic purposes should be highly sensitive and selective as well as simple, reproducible and inexpensive. However, it is practically almost impossible to satisfy
Copyright $\odot$ Experimental Neurobiology 2020.

www.enjournal.org
This is an Open Access article distributed under the terms of the Creative Commons Attribution Non-Commercial License (http://creativecommons.org/licenses/by-nc/4.0) which permits unrestricted non-commercial use, distribution, and reproduction in any medium, provided the original work is properly cited. 
all these criteria. Therefore, the identification of better biomarkers is essential and related studies are being conducted extensively. Currently, proteomic and metabolomic studies to identify whole target material in the samples are possible because of the advancement in liquid chromatography (LC) and mass spectrometry (MS), enabling the rapid and unbiased identification of biomarker candidates.

There are several tools to analyze bioactive substances in urine depending on the chemical identity of the target material. MS provides the best sensitivity, selectivity and quantitative identification capabilities to analyze the most bioactive compounds from proteins to simple metabolic chemicals. Sometimes, MS can be used with LC or gas chromatography (GC). However, these apparatuses are very expensive and require skilled manpower to run them. Enzyme-linked immunosorbent assay (ELISA) is also a sensitive method to quantitatively detect various metabolic substances. Although a specific antibody against the target substance is a prerequisite for ELISA, if the target is decided and the antibody is available, ELISA can be easily done even in a small laboratory. However, to designate a specific substance as a biomarker, a high-throughput method or an educated guess is necessary. Therefore, despite its cost, MS-based proteomic analysis and metabolic profiling of urine from patients with a specific disease is gaining prominence to identify a novel disease-specific biomarker [14-16]. If the target material is nucleic acid, next generation sequencing or small RNA sequencing can be a tool for a high-throughput screening method [17]. However, there is no such study with urine yet, although miRNA studies using CSF have been reported $[18,19]$. When the target material is a specific protein, western blot analysis can be a simple and cost-efficient method although accurate quantification of the result could be difficult. This can be applied to specific $A \beta$ peptides or phosphor-Taus for $\mathrm{AD}$ and monomeric of oligomeric forms of a-synuclein for PD because of the well-known causal relationship between these proteins and the corresponding disease $[20,21]$. In addition, a recent study reported the use of an antibody labelled with fluorescent dye to detect $\mathrm{A} \beta_{42}$ in ELISA kits [22].

Low levels of urinary bioactive material make biomarker detection more challenging. However, it can be partially solved by increasing the concentration of urine by proper methods such as microfiltration or fractionation of active material [13,23]. Another method to solve this problem is to utilize urinary exosomes $[8,11$, 24-26] which contain various cellular metabolites such as proteins, nucleic acids and lipids whose compositions reflect the physiology of cells from which they were originated. Such metabolites in urine exosomes are generally higher than their urinary concentrations [27]. Therefore, urinary exosomes may be critical sources to develop a specific, non-invasive and cost-effective disease diagnostic and monitoring tools [28]. Accordingly, urinary exosomes were investigated for their diagnostic and therapeutic potentials in NDDs [1]. In fact, increased levels of DJ-1 and phosphorylation of S1292 (p-S1292) LRRK2 were observed in the urinary exosomes of male PD patients $[8,12]$. In addition, systemic approaches with proteomic analysis of urine exosomes from patients have identified SNAP23 and calbindin as novel PD biomarkers for PD [6] and higher levels of $\mathrm{A} \beta_{1-42}$ and $\mathrm{p}-\mathrm{S} 396$-Tau for $\mathrm{AD}$ [29].

In the following sections, we briefly introduce recent efforts to identify urine biomarker candidates to diagnose NDD that are present in specific bioactive substances (e.g., metabolites, proteins/ peptides, miRNAs and DNAs) and in exosomes (Table 1). The purpose of this review is brief, but extensive introduction on this subject, and therefore, more detailed information is available in the references listed here. In addition, although NDD includes AD, PD, ALS and HD and others, we limit our discussion to PD and AD as these are the two most common NDDs and their major pathogenic mechanisms, accumulation of misfolded/unfolded proteins and increase of oxidative stress, are common to most of the NDDs [30].

\section{Metabolites}

Metabolomics is one of the emerging -omics that aims to identify most metabolites within a target sample and their change. Luan et al. [14] analyzed 157 urine samples, including 92 samples from PD patients and 65 samples from normal control subjects with GC-MS and LC-MS. The resulting metabolic profiles identified 18 metabolites which are differentially expressed between PD and controls [14].

Dopamine and its metabolites were detected in urine as well as in CSF and plasma [31]. Urinary dopamine was higher in PD patients under L-DOPA treatment as expected [32]. Besides, the concentrations of 5- and 6-hydroxydopamine in the urine from LDOPA treated PD patients were also higher than those from nontreated patients and from normal controls [33], discouraging the use of dopamine as a PD biomarker. A recent report identified kynurenine as a urinary PD biomarker [34]. The kynurenine pathway had been suggested to correlate with PD mechanism [35] and the alterations of kynurenine levels in CSF and blood from PD patients have been reported [36,37].

APP transgenic mouse, a well-established AD animal model, was widely used to study the metabolomic changes related to $\mathrm{AD}$ [38]. A significant increase of 5-hydroxyindoleacetic acid (5-HIAA), the major metabolite of serotonin, has been reported in the urine of AD model mice [39]. Another promising candidate is urine formaldehyde which shows inverse correlation with Mini Mental State Examination (MMSE) scores [40-42]. The human urine study [43] 
Table 1. Representative studies of urine biomarker analysis

\begin{tabular}{|c|c|c|c|c|c|c|c|}
\hline \multirow{2}{*}{$\begin{array}{c}\text { Target } \\
\text { substance }\end{array}$} & \multirow{2}{*}{ Disease } & \multirow{2}{*}{ Detection method } & \multirow{2}{*}{ Target } & \multicolumn{2}{|c|}{ Number of case } & \multirow{2}{*}{ Conclusion* } & \multirow{2}{*}{$\begin{array}{c}\text { Refer- } \\
\text { ence }\end{array}$} \\
\hline & & & & Disease & Control & & \\
\hline \multirow[t]{8}{*}{ Metabolites } & \multirow[t]{4}{*}{$\mathrm{AD}$} & $\begin{array}{l}\text { UPLC coupled with qua- } \\
\text { druple time-of-flight MS }\end{array}$ & Mouse & 30 & 30 & $\begin{array}{l}\text { 5-hydroxyindoleacetic acid } \uparrow \text { and } \\
\text { change of other } 25 \text { metabolites }\end{array}$ & {$[39]$} \\
\hline & & LC-MS/MS targeting & Human & 32 & 74 & 3-HPMA/Cre $\downarrow$ & {$[85]$} \\
\hline & & $\begin{array}{l}\text { 3-HPMA, ELISA for AC- } \\
\text { Acro }\end{array}$ & & & & AC-Acro/Cre $\downarrow$ & \\
\hline & & Head-space GC/MS & Mouse & 38 & 34 & 1-octen-3-ol $\downarrow$ & {$[86]$} \\
\hline & \multirow[t]{4}{*}{$\mathrm{PD}$} & $\begin{array}{l}\text { Non-targeted metabolic } \\
\text { profiling and ELISA }\end{array}$ & Human & 92 & 65 & Biopyrrine $\uparrow$ & {$[87]$} \\
\hline & & ELISA for kynurenine & Human & 41 & 41 & Kynurenine $\uparrow$ & {$[34]$} \\
\hline & & LC-MS base & Human & 106 & 104 & $\begin{array}{l}\text { Cortisol } \uparrow, 11 \text {-deoxycortisol } \uparrow \text {, } \\
21 \text { - deoxycortisol } \uparrow, \text { histidine } \uparrow \text {, } \\
\text { urocanic acid } \uparrow, \text { imidazoleace- } \\
\text { tic acid } \uparrow, \text { hydroxy-phenylace- } \\
\text { tic acid } \uparrow\end{array}$ & {$[15]$} \\
\hline & & LC-MS \& GC-MS base & Human & 92 & 65 & $\begin{array}{l}\text { Change of } 18 \text { metabolites } \\
\text { (alanine, leucine, isoleucine, } \\
\text { aminobutyric acid, hydroxy- } \\
\text { tryptophan, cortisol, etc.) }\end{array}$ & {$[14]$} \\
\hline \multirow[t]{2}{*}{ Nucleic acids } & $\mathrm{AD}$ & $\begin{array}{l}\text { Ultra-performance } \\
\text { LC--tandem MS }\end{array}$ & Human & 53 & 27 & 8-OHdG $\uparrow$ and 8 -OHdG/2dG $\uparrow$ & {$[44]$} \\
\hline & $\mathrm{PD}$ & ELISA for 8-OHdG & Human & 72 & 48 & (8-OHdG)/creatinine $\uparrow$ & {$[76]$} \\
\hline \multirow[t]{8}{*}{ Protein } & \multirow[t]{4}{*}{$\mathrm{AD}$} & LC-MS/MS & Mouse & NS & NS & $\begin{array}{l}\text { Kallikrein-1 ( } \uparrow \text { or } \downarrow \text { depending } \\
\text { on mouse age) }\end{array}$ & {$[7]$} \\
\hline & & ELSIA for AD7c-NTP & Human & 66 & 134 & $\mathrm{AD} 7 \mathrm{c}-\mathrm{NTP} \uparrow$ & $\begin{array}{l}{[52,54,} \\
56,57, \\
88]\end{array}$ \\
\hline & & LC-MS/MS & Human & 18 & 18 & $\begin{array}{c}\text { Change of } 73 \text { proteins }(>2 \text {-fold } \uparrow) \\
\text { and } 36 \text { proteins }(<0.5 \text {-fold } \downarrow)\end{array}$ & {$[16]$} \\
\hline & & $\begin{array}{l}2 \text { gene expression data of } \\
\text { brain samples } \rightarrow \text { iTRAQ } \\
\text { of urine samples }\end{array}$ & Human & 20 (urine) & 20 (urine) & SPP1 $\downarrow$, GSN $\uparrow$, and IGFBP7 $\uparrow$ & {$[51]$} \\
\hline & \multirow[t]{4}{*}{ PD } & EV-MS/MS & Human & $\begin{array}{l}\text { Discovery: } 28 \\
\text { replication:51 }\end{array}$ & $\begin{array}{l}\text { Discovery: } 22 \\
\text { replication:57 }\end{array}$ & SNAP23 $\uparrow$, and calbindin $\uparrow$ & {$[6]$} \\
\hline & & Scalable and sensitive MS & Human & $\begin{array}{l}\text { Cohort 1: } 35 \text { HC, } \\
\text { 16 NMC, } 40 \text { iPD, } \\
\text { 28 LRRK2 PD; } \\
\text { Cohort 2: } 26 \text { HC, } \\
\text { 37 NMC, } 29 \text { iPD, } \\
\text { 23 LRRK2 PD }\end{array}$ & & $\begin{array}{l}\mathrm{PPIB} \uparrow \text {, apolipoproteins } \uparrow, \mathrm{VGF} \downarrow \\
\text { in iPD; } \\
\mathrm{ALPI} \uparrow,(\mathrm{HEXA}, \mathrm{HEXB}, \mathrm{GM} 2 \mathrm{~A} \\
\text { and GCase } \uparrow \text { in LRRK2 PD }\end{array}$ & {$[58]$} \\
\hline & & $\begin{array}{l}\text { ELISA for oligomer, fila- } \\
\text { ment and total } a-\text { syn }\end{array}$ & Human & 21 & 11 & $\begin{array}{l}\text { Specific filament form of } \\
\text { a-synuclein } \uparrow\end{array}$ & {$[13]$} \\
\hline & & Western blot & Human & 26 & 21 & DJ- $1 \uparrow$ (in Male only) & {$[8]$} \\
\hline
\end{tabular}

*Some targets are omitted because of space limit.

NS, not specified; 2dG, 2'-deoxyguanosine; 3-HPMA, 3-HPMA3-Hydroxypropyl mercapturic acid; Cre, creatinine; AC-Acro, amino acid-conjugated acrolein; 8-OHdG, 8-hydroxy-2'-deoxyguanosine; AD7c-NTP, AD-associated Neuronal Thread Protein; EV, Extracellular Vesicle; ELISA, Enzyme-Linked ImmunoSorbent Assay; HC, Healthy Controls; NMC, Non-Manifesting LRRK2 G2019S Carriers; iPD, idiopathic PD patients; LRRK2 PD, manifesting PD patients with LRRK2 G2019S.

suggested several metabolites in amino acid metabolism such as L-glutamine, 5-L-glutamylglycine and phospholipid metabolites as novel AD biomarkers. Oxidative compounds are also good candidates for $\mathrm{AD}$ biomarkers because, like $\mathrm{PD}$, oxidative stress is a major causative factor for $\mathrm{AD}$. One recent study reported significantly higher urinary levels of lipid peroxidation compounds in AD compared to control cases [44].

However, several metabolomic studies have suggested that some 
biomarker candidates are not disease-specific, indicating that they were also found with other neurodegenerative diseases in addition to the originally targeted disease [45]. This is predictable when one considers that the molecular mechanisms associated with pathogenesis of NDDs are frequently overlapped.

\section{Proteins}

Approximately 20\% of urinary proteins were derived from blood after renal filtration and proteins less than $20 \mathrm{KDa}$ can cross the kidney filtration barrier although most of them are reabsorbed. However, proteins bigger than $100 \mathrm{KDa}$ had been also detected in urine [46]. This implied the potential of urinary proteins to diagnose diseases in addition to renal diseases [47].

Efforts to identify biomarkers for AD or PD are conducted in two directions. One is to investigate whether well-known diseasespecific proteins (e.g., APP/A $\beta$ or Tau for AD, and $\alpha$-synuclein, LRRK2 or DJ-1 for PD) are present in different levels and another is a systemic approach such as proteomics to identify proteins showing different levels between patient and control samples. Specific forms of $A \beta$ peptides are neurotoxic and their presence in the brain is regarded as an early indicator of $\mathrm{AD}$ [48]. Oligomeric or high concentration of $\alpha$-synuclein has been wellknown to contribute to PD progression [49]. Monomeric or oligomeric forms of $\alpha$-synuclein were extensively investigated for their potentials as biomarkers in CSF and plasma [50]. However, the results were inconsistent. In contrast, there are few reports on urinary a-synuclein, which might be due to low concentration of a-synuclein. Very recently, we observed the presence of a-synuclein in the urine after 10 -fold concentration of urine through microfiltration and reported the significant increase of filamentous $\alpha$-synuclein in PD urine samples [13]. In addition, we have reported the increase of DJ-1 in urine from male PD patients [8].

Several MS proteomics approaches could identify gene ontology terms showing significant differences between patient and control samples via gene ontology enrichment analyses in addition to identification of an individual biomarker candidate(s). For example, matrix metalloproteinase signaling, lipoprotein metabolism and heat shock protein 90 signaling pathways were related to $\mathrm{AD}$ [16]. An interesting study identified differentially expressed gene in $\mathrm{AD}$ brain through computational analysis and then verified the differences in the levels of urinary proteins encoded by these genes [51]. They found that osteopontin, gelsolin and insulin-like growth factor-binding protein 7 were differentially present in the urine of $\mathrm{AD}$ patients [51]. This type of approach which identifies target substances in the brain or CSF and then confirms their differences in urine between patients and healthy controls may provide a new direction to identify novel urine biomarkers. Increased levels of Alzheimer-associated neuronal thread protein (AD7c-NTP) in urine are detected in the $\mathrm{AD}$ samples in several independent studies [52-54]. A company called Nymox had obtained European approval to sell an Enzyme Immunoassay (EIA) kit to detect urinary NTP levels to diagnose AD, but there was a controversy [55] as an independent study found that the test tended to show low specificity and sensitivity. However, the potential of AD7c-NTP as a urine biomarker for $\mathrm{AD}$ as well as mild cognitive impairment (MCI) is still being actively pursued [56,57].

One of the most recent and extensive PD proteomic profiling has been reported by Winter et al. [58]. They analyzed more than 200 urine samples from two independent cohorts consisting of LRRK2 WT healthy controls, non-manifesting carriers of LRRK2 G2019S, a major genetic factor for PD pathogenesis, idiopathic PD patients and PD patients with the LRRK2 G2019S mutation through scalable and sensitive MS-based proteomics. Their results indicated that urinary proteomics was sufficient to distinguish the presence of either LRRK2 mutation or the disease, confirming that urinary proteomics has the potential to identify a novel PD biomarker [58]. The possibility of different levels of modified proteins such as phosphorylation or oxidation was also investigated. Hyperphosphorylation of Tau is critical for $\mathrm{AD}$ pathogenesis and a higher level of phosphorylation of S396 (p-S396) in Tau in the urinary exosomes of AD patients was reported [29]. p-S1292 LRRK2 is critical for its PD pathogenesis and higher levels of p-S1292 LRRK2 in the urinary exosomes of PD patients were reported [12]. Similarly, a higher level of oxidized DJ-1 in the urine of PD patients was also reported [59].

\section{RNAs and DNAs}

miRNAs are small non-coding RNAs that regulate the expression of their target genes [60]. Various miRNAs have been reported to alter the expression of genes related to PD such as mitochondria dysfunction, $\alpha$-synuclein regulation, oxidative stress and neuroinflammation [61]. Their presence in CSF, saliva, plasma and urine promoted the investigation of miRNAs for their biomarker potential for NDDs [3]. One systemic study searched all miRNAs reported to be significantly deregulated in the blood and compared them to the miRNAs deregulated in the brain at Braak Stage III of AD. Using this approach, 10 miRNAs were identified to be dysregulated in early AD stage [62]. Other studies also proved the potential of circulating miRNAs as NDD biomarkers $[17,28]$. It is an additional advantage that urinary miRNAs are relatively stable even after 10 cycles of freezing and thawing [63]. Although their low concentration in the urine can be a disadvantage [64], it can be overcome by utilizing miRNAs in the urinary exosome where bio- 
active substances are relatively concentrated. However, there are few reports to investigate urinary miRNAs as NDD biomarkers.

Urinary mRNAs are considered as inappropriate biomarkers because of their instabilities. However, the instability issue can be circumvented by the pretreatment of urine by the addition of guanidinium thiocyanate [65], or by their isolation from urinary exosomes or cells present in the urine. Accordingly, specific mRNAs as well as their splice variants were reported as specific biomarkers of muscular dystrophies [66] and renal fibrosis [67]. Urinary genomic DNAs (gDNAs) mostly were derived from cells secreted to the urines and mutations in such gDNAs were used to detect bladder cancer [68]. A recent approach showed that purification and highthroughput sequencing of cell free urinary DNAs are possible [69]. Detection of differences of gDNAs from the urine samples of the diseases and the healthy controls could be possible, if any.

The mitochondria have their own DNA to encode several critical enzymes for ATP synthesis and change of mitochondrial (mt) DNA has been suggested as AD and PD biomarkers. Leakage of mtDNA is associated with mitochondrial impairment. Cell-free mtDNA can be secreted in the biofluid and detected with specific primer sets through PCR. Various mtDNA mutations in the brain were reported as risk factors of AD [70]. Decrease of cell-free mtDNA copies has been also observed in PD CSF samples [71]. This was confirmed by Podlesniy et al. and they further showed that the copy number of mtDNA in CSF was significantly higher in PD patients with G2019S mutation group than the idiopathic PD or healthy G2019S carrier group [72]. It is yet to be investigated whether these changes are maintained in urine cell-free mtDNAs.

Oxidative stress is a major cause of both PD and AD and oxidized DNA can be generated during disease progression. 8-hydroxy-2'-deoxyguanosine (8-OHdG) is the most studied form of oxidized DNA and its urinary level has been used to measure oxidative stress in human [73]. Consequently, significantly higher levels of 8-OHdG in the urine of PD [74] and MCI-AD [75] cases were observed. In addition, the level of urinary 8 -OHdG progressively increased as PD advanced [76]. Interestingly, the concentrations of urinary 8-oxo-7,8-dihydroguanine (8-oxoGua) and miR_6778_5p in samples of workers exposed to organic solvents showed a significant negative association [77], suggesting a possibility of similar approach to combine two different factors in NDD urines.

\section{CONSIDERATIONS}

There are several points to consider before the practical application to screen urinary NDD biomarkers. First, quality control of the urine sample is critical because urinary proteins are easily af- fected by complicated factors such as sampling time, medicine and diet, especially in human samples. Before analysis, urine samples such as proteinuria or lipiduria should be excluded because such conditions may suggest a kidney problem [47]. For urinary analysis, the first urine in the morning is preferred. Several studies tested for consistency of urine proteins and metabolites, after repeated cycles of freezing and thawing or sampling at different times $[8$, 78-80]. Their results implied that most, if not all, bioactive materials are relatively stable after several cycles of freezing and thawing, but the sampling time mostly matters $[63,81]$. However, if there is no absolute reason to obtain the first urine in the morning, sampling the urines at convenient times may be more practical because collection of the first urine in the morning needs additional efforts and limits cases of patients who can contribute the urine. In addition, a standard protocol for the processes to collect, handle and store specimens should be established before analysis to reduce the inconsistency of results between studies. Secondly, some candidates were identified in other diseases as well as the target disease, suggesting that they might be involved in the NDD progression process itself rather than the disease-specific $[45,75,76]$. Therefore, when a biomarker candidate is identified in the urine, it is important to further confirm it in other samples or different diseases. Thirdly, a combination of multimodal biomarkers from urine as well as other biofluids might provide a better selective window. For example, addition of certain miRNA levels to $A \beta_{42}: T$ tau measures in CSF improved classification of AD [18]. Similarly, a combination of levels of serum BDNF and urine AD7c-NTP in mild cognitive impairment (MCI) cases increases its prediction to their AD evolvement [9]. For this purpose, before IRB application, planning analysis with both urine and other biosamples such as plasma or CSF might be desirable. Finally, the selection of proper normalized controls is critical. Although house-keeping genes such as GAPDH or $\beta$-actin are generally used as normalized genes for most western blot or PCR analysis, there are few reports on this subject, and moreover, the use of GAPDH as a urinary normalizer was contradictory $[65,81]$. If the intact urine is used for analysis without any further process, the used volume itself can function as a normalizer $[71,72]$. Based on this, it is desirable that processing of urine samples before analysis is minimal.

We recommend other references for more detail reviews $[6,44$, 82-84].

\section{CONCLUSION}

Novel biomarkers with higher specificity and sensitivity that can be easily tested at a reasonable cost are urgently needed for NDDs. Since urine can be invasively sampled in abundance, it can 
be a good biofluid to identify biomarkers. Recent technological advances allow for the systematic, holistic, and unbiased characterization of alterations in RNAs as well as genes, proteins and metabolites in the urine associated with the identification of novel biomarkers and disease conditions, making these approaches more promising. There are even a few biomarkers such as urinary formaldehyde and 8-OHdG showing correlation with severity of the diseases $[42,76]$, suggesting their potential as markers to predict the therapeutic effect. However, it is required to confirm a candidate through independent studies.

\section{ACKNOWLEDGEMENTS}

Firstly, we would like to apologize for the exclusion of important results on this topic due to the space limit. We thank the members of the Inam Neuroscience Research Center for their helpful discussion and Editage (www.editage.co.kr) for English language editing. This study was supported by the Wonkwang University in 2019.

\section{CONFLICT OF INTEREST}

The authors declare no conflict of interest.

\section{REFERENCES}

1. Izadpanah M, Seddigh A, Ebrahimi Barough S, Fazeli SAS, Ai J (2018) Potential of extracellular vesicles in neurodegenerative diseases: diagnostic and therapeutic indications. J Mol Neurosci 66:172-179.

2. Khalil M, Teunissen CE, Otto M, Piehl F, Sormani MP, Gattringer T, Barro C, Kappos L, Comabella M, Fazekas F, Petzold A, Blennow K, Zetterberg H, Kuhle J (2018) Neurofilaments as biomarkers in neurological disorders. Nat Rev Neurol 14:577-589.

3. Danborg PB, Simonsen AH, Waldemar G, Heegaard NH (2014) The potential of microRNAs as biofluid markers of neurodegenerative diseases--a systematic review. Biomarkers 19:259-268.

4. Simonsen AH, Kuiperij B, El-Agnaf OM, Engelborghs S, Herukka SK, Parnetti L, Rektorova I, Vanmechelen E, Kapaki E, Verbeek M, Mollenhauer B (2016) The utility of a-synuclein as biofluid marker in neurodegenerative diseases: a systematic review of the literature. Biomark Med 10:19-34.

5. Carlyle BC, Trombetta BA, Arnold SE (2018) Proteomic approaches for the discovery of biofluid biomarkers of neurodegenerative dementias. Proteomes 6:32.
6. Wang S, Kojima K, Mobley JA, West AB (2019) Proteomic analysis of urinary extracellular vesicles reveal biomarkers for neurologic disease. EBioMedicine 45:351-361.

7. Zhang F, Wei J, Li X, Ma C, Gao Y (2018) Early candidate urine biomarkers for detecting Alzheimer's disease before amyloid- $\beta$ plaque deposition in an APP (swe)/PSEN1dE9 transgenic mouse model. J Alzheimers Dis 66:613-637.

8. Ho DH, Yi S, Seo H, Son I, Seol W (2014) Increased DJ-1 in urine exosome of Korean males with Parkinson's disease. Biomed Res Int 2014:704678.

9. Wang C, Cui Y, Yang J, Zhang J, Yuan D, Wei Y, Li Y, Duo Y, Li S, Zhu W, Zheng L (2015) Combining serum and urine biomarkers in the early diagnosis of mild cognitive impairment that evolves into Alzheimer's disease in patients with the apolipoprotein E $€ 4$ genotype. Biomarkers 20:84-88.

10. Yang S, Xia C, Li S, Du L, Zhang L, Hu Y (2014) Mitochondrial dysfunction driven by the LRRK2-mediated pathway is associated with loss of Purkinje cells and motor coordination deficits in diabetic rat model. Cell Death Dis 5:e1217.

11. Wang S, West AB (2019) Caught in the act: LRRK2 in exosomes. Biochem Soc Trans 47:663-670.

12. Wang S, Liu Z, Ye T, Mabrouk OS, Maltbie T, Aasly J, West AB (2017) Elevated LRRK2 autophosphorylation in brainderived and peripheral exosomes in LRRK2 mutation carriers. Acta Neuropathol Commun 5:86.

13. Nam D, Lee JY, Lee M, Kim J, Seol W, Son I, Ho DH (2020) Detection and assessment of $\alpha$-synuclein oligomers in the urine of Parkinson's disease patients. J Parkinsons Dis 10:981991.

14. Luan H, Liu LF, Tang Z, Zhang M, Chua KK, Song JX, Mok VC, Li M, Cai Z (2015) Comprehensive urinary metabolomic profiling and identification of potential noninvasive marker for idiopathic Parkinson's disease. Sci Rep 5:13888.

15. Luan H, Liu LF, Meng N, Tang Z, Chua KK, Chen LL, Song JX, Mok VC, Xie LX, Li M, Cai Z (2015) LC-MS-based urinary metabolite signatures in idiopathic Parkinson's disease. J Proteome Res 14:467-478.

16. Watanabe Y, Hirao Y, Kasuga K, Tokutake T, Semizu Y, Kitamura K, Ikeuchi T, Nakamura K, Yamamoto T (2019) Molecular network analysis of the urinary proteome of Alzheimer's disease patients. Dement Geriatr Cogn Dis Extra 9:53-65.

17. Roser AE, Caldi Gomes L, Schünemann J, Maass F, Lingor P (2018) Circulating miRNAs as diagnostic biomarkers for Parkinson's disease. Front Neurosci 12:625.

18. Wiedrick JT, Phillips JI, Lusardi TA, McFarland TJ, Lind B, Sandau US, Harrington CA, Lapidus JA, Galasko DR, Quinn JF, Saugstad JA (2019) Validation of MicroRNA biomarkers 
for Alzheimer's disease in human cerebrospinal fluid. J Alzheimers Dis 67:875-891.

19. Burgos KL, Javaherian A, Bomprezzi R, Ghaffari L, Rhodes S, Courtright A, Tembe W, Kim S, Metpally R, Van KeurenJensen K (2013) Identification of extracellular miRNA in human cerebrospinal fluid by next-generation sequencing. RNA 19:712-722.

20. Takata M, Nakashima M, Takehara T, Baba H, Machida K, Akitake Y, Ono K, Hosokawa M, Takahashi M (2008) Detection of amyloid beta protein in the urine of Alzheimer's disease patients and healthy individuals. Neurosci Lett 435:126130.

21. Atik A, Stewart T, Zhang J (2016) Alpha-synuclein as a biomarker for Parkinson's disease. Brain Pathol 26:410-418.

22. Chan HN, Xu D, Ho SL, Wong MS, Li HW (2017) Ultrasensitive detection of protein biomarkers for diagnosis of Alzheimer's disease. Chem Sci 8:4012-4018.

23. Harpole M, Davis J, Espina V (2016) Current state of the art for enhancing urine biomarker discovery. Expert Rev Proteomics 13:609-626.

24. Wang Z, Hill S, Luther JM, Hachey DL, Schey KL (2012) Proteomic analysis of urine exosomes by multidimensional protein identification technology (MudPIT). Proteomics 12:329338.

25. van Balkom BW, Pisitkun T, Verhaar MC, Knepper MA (2011) Exosomes and the kidney: prospects for diagnosis and therapy of renal diseases. Kidney Int 80:1138-1145.

26. Russo I, Bubacco L, Greggio E (2012) Exosomes-associated neurodegeneration and progression of Parkinson's disease. Am J Neurodegener Dis 1:217-225.

27. Merchant ML, Powell DW, Wilkey DW, Cummins TD, Deegens JK, Rood IM, McAfee KJ, Fleischer C, Klein E, Klein JB (2010) Microfiltration isolation of human urinary exosomes for characterization by MS. Proteomics Clin Appl 4:84-96.

28. Cheng L, Quek CY, Sun X, Bellingham SA, Hill AF (2013) The detection of microRNA associated with Alzheimer's disease in biological fluids using next-generation sequencing technologies. Front Genet 4:150.

29. Sun R, Wang H, Shi Y, Gao D, Sun Z, Chen Z, Jiang H, Zhang J (2019) A pilot study of urinary exosomes in Alzheimer's disease. Neurodegener Dis 19:184-191.

30. Kim GH, Kim JE, Rhie SJ, Yoon S (2015) The role of oxidative stress in neurodegenerative diseases. Exp Neurobiol 24:325340 .

31. Bishnoi M, Chopra K, Kulkarni SK (2007) Possible antioxidant and neuroprotective mechanisms of zolpidem in attenuating typical anti-psychotic-induced orofacial dyskinesia: a biochemical and neurochemical study. Prog Neuropsychopharmacol Biol Psychiatry 31:1130-1138.

32. Nichkova M, Wynveen PM, Marc DT, Huisman H, Kellermann GH (2013) Validation of an ELISA for urinary dopamine: applications in monitoring treatment of dopaminerelated disorders. J Neurochem 125:724-735.

33. Andrew R, Watson DG, Best SA, Midgley JM, Wenlong H, Petty RK (1993) The determination of hydroxydopamines and other trace amines in the urine of Parkinsonian patients and normal controls. Neurochem Res 18:1175-1177.

34. Bai JH, Zheng YL, Yu YP (2020) Urinary kynurenine as a biomarker for Parkinson's disease. Neurol Sci. doi: 10.1007/ s10072-020-04589-X.

35. Tan L, Yu JT, Tan L (2012) The kynurenine pathway in neurodegenerative diseases: mechanistic and therapeutic considerations. J Neurol Sci 323:1-8.

36. Widner B, Leblhuber F, Fuchs D (2002) Increased neopterin production and tryptophan degradation in advanced Parkinson's disease. J Neural Transm (Vienna) 109:181-189.

37. Chang KH, Cheng ML, Tang HY, Huang CY, Wu YR, Chen CM (2018) Alternations of metabolic profile and kynurenine metabolism in the plasma of Parkinson's disease. Mol Neurobiol 55:6319-6328.

38. Kim M, Legido-Quigley C (2018) Small molecule biomarkers in Alzheimer's disease. OCL 25:D404.

39. Yu J, Kong L, Zhang A, Han Y, Liu Z, Sun H, Liu L, Wang X (2017) High-throughput metabolomics for discovering potential metabolite biomarkers and metabolic mechanism from the APPswe/PS1dE9 transgenic model of Alzheimer's disease. J Proteome Res 16:3219-3228.

40. Tong Z, Wang W, Luo W, Lv J, Li H, Luo H, Jia J, He R (2017) Urine formaldehyde predicts cognitive impairment in poststroke dementia and Alzheimer's disease. J Alzheimers Dis 55:1031-1038.

41. Ai L, Tan T, Tang Y, Yang J, Cui D, Wang R, Wang A, Fei X, Di Y, Wang X, Yu Y, Zhao S, Wang W, Bai S, Yang X, He R, Lin W, Han H, Cai X, Tong Z (2019) Endogenous formaldehyde is a memory-related molecule in mice and humans. Commun Biol 2:446.

42. Yu J, Su T, Zhou T, He Y, Lu J, Li J, He R (2014) Uric formaldehyde levels are negatively correlated with cognitive abilities in healthy older adults. Neurosci Bull 30:172-184.

43. Cui Y, Liu X, Wang M, Liu L, Sun X, Ma L, Xie W, Wang C, Tang S, Wang D, Wu Q (2014) Lysophosphatidylcholine and amide as metabolites for detecting Alzheimer disease using ultrahigh-performance liquid chromatography-quadrupole time-of-flight mass spectrometry-based metabonomics. J 
Neuropathol Exp Neurol 73:954-963.

44. Peña-Bautista C, Vigor C, Galano JM, Oger C, Durand T, Ferrer I, Cuevas A, López-Cuevas R, Baquero M, López-Nogueroles M, Vento M, Hervás-Marín D, García-Blanco A, CháferPericás C (2019) New screening approach for Alzheimer's disease risk assessment from urine lipid peroxidation compounds. Sci Rep 9:14244.

45. Cova I, Priori A (2018) Diagnostic biomarkers for Parkinson's disease at a glance: where are we? J Neural Transm (Vienna) 125:1417-1432.

46. Yan L, Borregaard N, Kjeldsen L, Moses MA (2001) The high molecular weight urinary matrix metalloproteinase (MMP) activity is a complex of gelatinase B/MMP-9 and neutrophil gelatinase-associated lipocalin (NGAL). Modulation of MMP-9 activity by NGAL. J Biol Chem 276:37258-37265.

47. Julian BA, Suzuki H, Suzuki Y, Tomino Y, Spasovski G, Novak J (2009) Sources of urinary proteins and their analysis by urinary proteomics for the detection of biomarkers of disease. Proteomics Clin Appl 3:1029-1043.

48. Chen GF, Xu TH, Yan Y, Zhou YR, Jiang Y, Melcher K, Xu HE (2017) Amyloid beta: structure, biology and structure-based therapeutic development. Acta Pharmacol Sin 38:1205-1235.

49. Froula JM, Castellana-Cruz M, Anabtawi NM, Camino JD, Chen SW, Thrasher DR, Freire J, Yazdi AA, Fleming S, Dobson CM, Kumita JR, Cremades N, Volpicelli-Daley LA (2019) Defining $\alpha$-synuclein species responsible for Parkinson's disease phenotypes in mice.J Biol Chem 294:10392-10406.

50. Kang W, Chen W, Yang Q, Zhang L, Zhang L, Wang X, Dong F, Zhao Y, Chen S, Quinn TJ, Zhang J, Chen S, Liu J (2016) Salivary total $\alpha$-synuclein, oligomeric $a$-synuclein and SNCA variants in Parkinson's disease patients. Sci Rep 6:28143.

51. Yao F, Hong X, Li S, Zhang Y, Zhao Q, Du W, Wang Y, Ni J (2018) Urine-based biomarkers for Alzheimer's disease identified through coupling computational and experimental methods. J Alzheimers Dis 65:421-431.

52. Youn YC, Park KW, Han SH, Kim S (2011) Urine neural thread protein measurements in Alzheimer disease. J Am Med Dir Assoc 12:372-376.

53. Ma L, Chen J, Wang R, Han Y, Zhang J, Dong W, Zhang X, Wu Y, Zhao Z (2015) The level of Alzheimer-associated neuronal thread protein in urine may be an important biomarker of mild cognitive impairment. J Clin Neurosci 22:649-652.

54. Ghanbari H, Ghanbari K, Beheshti I, Munzar M, Vasauskas A, Averback P (1998) Biochemical assay for AD7C-NTP in urine as an Alzheimer's disease marker. J Clin Lab Anal 12:285-288.

55. Butcher J (2007) Urine tests for Alzheimer's disease--are they fool's gold? Lancet Neurol 6:106-107.

56. Ku BD, Kim H, Kim YK, Ryu HU (2020) Comparison of urinary Alzheimer-associated neural thread protein (AD7cNTP) levels between patients with amnestic and nonamnestic mild cognitive impairment. Am J Alzheimers Dis Other Demen 35:1533317519880369.

57. Zhang N, Zhang L, Li Y, Gordon ML, Cai L, Wang Y, Xing M, Cheng Y (2017) Urine AD7c-NTP predicts amyloid deposition and symptom of agitation in patients with Alzheimer's disease and mild cognitive impairment. J Alzheimers Dis 60:87-95.

58. Winter S, Karayel O, Strauss MT, Padmanabhan S, Surface M, Merchant K, Alcalay RN, Mann M (2020) Urinary proteome profiling for stratifying patients with familial Parkinson's disease. bioRxiv. doi: 10.1101/2020.08.09.243584.

59. Jang J, Jeong S, Lee SI, Seol W, Seo H, Son I, Ho DH (2018) Oxidized DJ-1 levels in urine samples as a putative biomarker for Parkinson's disease. Parkinsons Dis 2018:1241757.

60. Nelson PT, Wang WX, Rajeev BW (2008) MicroRNAs (miRNAs) in neurodegenerative diseases. Brain Pathol 18:130-138.

61. Arshad AR, Sulaiman SA, Saperi AA, Jamal R, Mohamed Ibrahim N, Abdul Murad NA (2017) MicroRNAs and target genes as biomarkers for the diagnosis of early onset of Parkinson disease. Front Mol Neurosci 10:352.

62. Swarbrick S, Wragg N, Ghosh S, Stolzing A (2019) Systematic review of miRNA as biomarkers in Alzheimer's disease. Mol Neurobiol 56:6156-6167.

63. Mall C, Rocke DM, Durbin-Johnson B, Weiss RH (2013) Stability of miRNA in human urine supports its biomarker potential. Biomark Med 7:623-631.

64. Weber JA, Baxter DH, Zhang S, Huang DY, Huang KH, Lee MJ, Galas DJ, Wang K (2010) The microRNA spectrum in 12 body fluids. Clin Chem 56:1733-1741.

65. Bai VU, Kaseb A, Tejwani S, Divine GW, Barrack ER, Menon M, Pardee AB, Reddy GP (2007) Identification of prostate cancer mRNA markers by averaged differential expression and their detection in biopsies, blood, and urine. Proc Natl Acad Sci U S A 104:2343-2348.

66. Antoury L, Hu N, Balaj L, Das S, Georghiou S, Darras B, Clark T, Breakefield XO, Wheeler TM (2018) Analysis of extracellular mRNA in human urine reveals splice variant biomarkers of muscular dystrophies. Nat Commun 9:3906.

67. Cao YH, Lv LL, Zhang X, Hu H, Ding LH, Yin D, Zhang YZ, Ni HF, Chen PS, Liu BC (2015) Urinary vimentin mRNA as a potential novel biomarker of renal fibrosis. Am J Physiol Renal Physiol 309:F514-F522.

68. Critelli R, Fasanelli F, Oderda M, Polidoro S, Assumma MB, 
Viberti C, Preto M, Gontero P, Cucchiarale G, Lurkin I, Zwarthoff EC, Vineis P, Sacerdote C, Matullo G, Naccarati A (2016) Detection of multiple mutations in urinary exfoliated cells from male bladder cancer patients at diagnosis and during follow-up. Oncotarget 7:67435-67448.

69. Dudley JC, Schroers-Martin J, Lazzareschi DV, Shi WY, Chen SB, Esfahani MS, Trivedi D, Chabon JJ, Chaudhuri AA, Stehr H, Liu CL, Lim H, Costa HA, Nabet BY, Sin MLY, Liao JC, Alizadeh AA, Diehn M (2019) Detection and surveillance of bladder cancer using urine tumor DNA. Cancer Discov 9:500-509.

70. Grazina M, Pratas J, Silva F, Oliveira S, Santana I, Oliveira C (2006) Genetic basis of Alzheimer's dementia: role of mtDNA mutations. Genes Brain Behav 5 Suppl 2:92-107.

71. Pyle A, Brennan R, Kurzawa-Akanbi M, Yarnall A, Thouin A, Mollenhauer B, Burn D, Chinnery PF, Hudson G (2015) Reduced cerebrospinal fluid mitochondrial DNA is a biomarker for early-stage Parkinson's disease. Ann Neurol 78:1000-1004.

72. Podlesniy P, Vilas D, Taylor P, Shaw LM, Tolosa E, Trullas R (2016) Mitochondrial DNA in CSF distinguishes LRRK2 from idiopathic Parkinson's disease. Neurobiol Dis 94:10-17.

73. Wu LL, Chiou CC, Chang PY, Wu JT (2004) Urinary 8-OHdG: a marker of oxidative stress to DNA and a risk factor for cancer, atherosclerosis and diabetics. Clin Chim Acta 339:1-9.

74. Bolner A, Pilleri M, De Riva V, Nordera GP (2011) Plasma and urinary HPLC-ED determination of the ratio of 8 -OHdG/2dG in Parkinson's disease. Clin Lab 57:859-866.

75. Peña-Bautista C, Tirle T, López-Nogueroles M, Vento M, Baquero M, Cháfer-Pericás C (2019) Oxidative damage of DNA as early marker of Alzheimer's disease. Int J Mol Sci 20:6136.

76. Sato S, Mizuno Y, Hattori N (2005) Urinary 8-hydroxydeoxyguanosine levels as a biomarker for progression of Parkinson disease. Neurology 64:1081-1083.

77. Sisto R, Capone P, Cerini L, Sanjust F, Paci E, Pigini D, Gatto MP, Gherardi M, Gordiani A, L'Episcopo N, Tranfo G, Chiarella P (2019) Circulating microRNAs as potential biomarkers of occupational exposure to low dose organic solvents. Toxicol Rep 6:126-135.
78. Rotter M, Brandmaier S, Prehn C, Adam J, Rabstein S, Gawrych K, Brüning T, Illig T, Lickert H, Adamski J, Wang-Sattler R (2017) Stability of targeted metabolite profiles of urine samples under different storage conditions. Metabolomics 13:4.

79. Zhang Y, Luo Y, Lu H, Wang N, Shen Y, Chen R, Fang P, Yu H, Wang C, Jia W (2015) Effect of freeze/thaw cycles on several biomarkers in urine from patients with kidney disease. Biopreserv Biobank 13:144-146.

80. Dolscheid-Pommerich RC, Klarmann-Schulz U, Conrad R, Stoffel-Wagner B, Zur B (2016) Evaluation of the appropriate time period between sampling and analyzing for automated urinalysis. Biochem Med (Zagreb) 26:82-89.

81. Hanke M, Kausch I, Dahmen G, Jocham D, Warnecke JM (2007) Detailed technical analysis of urine RNA-based tumor diagnostics reveals ETS2/urokinase plasminogen activator to be a novel marker for bladder cancer. Clin Chem 53:20702077.

82. An M, Gao Y (2015) Urinary biomarkers of brain diseases. Genomics Proteomics Bioinformatics 13:345-354.

83. Shao Y, Le W (2019) Recent advances and perspectives of metabolomics-based investigations in Parkinson's disease. Mol Neurodegener 14:3.

84. Pahuja G, Nagabhushan TN, Prasad B (2019) Early detection of Parkinson's disease by using SPECT imaging and biomarkers. J Intell Syst 29:1329-1344.

85. Yoshida M, Higashi K, Kuni K, Mizoi M, Saiki R, Nakamura M, Waragai M, Uemura K, Toida T, Kashiwagi K, Igarashi K (2015) Distinguishing mild cognitive impairment from Alzheimer's disease with acrolein metabolites and creatinine in urine. Clin Chim Acta 441:115-121.

86. Kimball BA, Wilson DA, Wesson DW (2016) Alterations of the volatile metabolome in mouse models of Alzheimer's disease. Sci Rep 6:19495.

87. Luan H, Liu LF, Tang Z, Mok VC, Li M, Cai Z (2015) Elevated excretion of biopyrrin as a new marker for idiopathic Parkinson's disease. Parkinsonism Relat Disord 21:1371-1372.

88. de la Monte SM, Wands JR (2002) The AD7C-NTP neuronal thread protein biomarker for detecting Alzheimer's disease. Front Biosci 7:d989-d996. 